\title{
Testing financial market efficiency
}

\author{
Islem Boutabba, \\ Department of Management, IHEC, University of Carthage, Tunisia.
}

\begin{abstract}
Since the birth of the financial literature until the 1970s, the efficient market hypothesis has been regarded as a central hypothesis. In the mid-1970s, there were theoretical and empirical evidence stating that the EMH seems untouchable. However, recently there has been an emergence of arguments doubting the EMH. The EMH implicitly indicates that stock prices can follow a random walk. Currently, financial theory has shown that stock prices do not follow a random walk.

In this regard, our empirical study rejected the hypothesis of a random walk for 27 indices out of 28 studied. We confirm that the studied indices time series do not follow a random walk, and therefore we reject the financial markets efficiency hypothesis in its weak form. This result corroborates those of Fama and French (1992.993), DeBondt and Thaler (1985), Lo and MacKinlay (1991), Jagadeesh and Titman (1993) and Shleifer and Vishny (1997). Therefore, financial markets efficiency hypothesis in its weak form is also rejected. This result is logical given the limited capacity of the classical theory in explaining abnormal returns such as bubbles, crashes and excess volatility.
\end{abstract}

\section{Indexing terms/Keywords}

Classical Finance, Random Walk, Efficient Market Hypothesis

\section{Academic Discipline And Sub-Disciplines}

Finance, Stock Market Efficiency

\section{SUBJECT CLASSIFICATION}

Financial subject classification

\section{TYPE (METHOD/APPROACH)}

Quantitative approach (Econometry).

\section{Council for Innovative Research}

Peer Review Research Publishing System

\section{Journal of Social Science Research}

Vol.3, No.3

editor@jssronline.com

www.cirworld.com, www.jssronline.com 


\section{INTRODUCTION}

The main challenge of transforming a centrally-planned economy is the establishment of a set of financial markets that should operate in a reasonably efficient manner. These markets play several roles in this transformation process. Not only do they act as a channel of investment funds through economy, but they also play a central role in the allocation of the richness of privatization during restructuring of the economy.

Many elements should be discussed while creating new financial markets. The type of trading system should be selected of which regulation and business structures are examples. When the market is established and is working efficiently there may be a little clear distinction between the different strategic options.

However, in the early days of a new market, it is clear that market participants are unlikely to act in accordance with the efficient markets paradigm (Cornelius, 1994). As these markets are new, trade is still very thin, disclosure practices of companies are very limited, and there are institutional barriers to trade. Therefore, market efficiency may not have taken place yet (Blaga (2012) and Aga and Kocaman (2011)).

As a first step to understanding these problems, a direct measure of efficiency degree can be used to model the learning process that we expect to occur in these markets. There is an extensive literature on testing efficient markets hypothesis (see Fama, 1970, Baillie 1989, Fama 1991, Campbell, Lo and McKinley 1997, Fama (1998)). Moreover, a number of recent studies have examined behavior of emerging markets equities. (See Bekaert and Harvey, 1995 and 1997 , Claessens, Dasgupta, Glen, 1995, Campbell, 1996, Hadi (2011), Harvey, 1995 and finally, the recent contribution of Jochum, Kirchgässner and Platek, 1999). However, we assume that the testing procedures used in most of these studies are not a successful approach to evaluate efficiency development in transition economies. Instead, we use a time-varying parameter model that can move from an inefficiency to efficiency indicator (and vice versa) like the change of parameters themselves, in line with recent contributions by Rockinger and Urga (2000.2001) and Zalewska-Mitura and Hall (1999). It is not unrealistic to assume that these markets start from an inefficient state, and then move to an efficient one. The adopted approach provides an indicator of market inefficiency degree and timing and speed of movement towards efficiency.

\section{1- MARKET EFFICIENCY TESTING METHODOLOGY}

\section{1-1 Market Efficiency Hypotheses:}

Our main goal is to test whether markets have evolved into some efficiency since their foundation.

We consider a model in which forecasting returns, as measured by autocorrelation, evolves over time. Since forecasting asset prices suggests that it is possible to make easy profits, several studies have investigated the impact of recurring factors in asset prices. Taylor (1986), Keim (1987), Fama (1991) and Fama (1998) review this literature. Fama (1970) considers that a market is efficient if prices reflect all available information. Roberts (1967) distinguishes between different forms of efficiency according to information considered. However, Malkiel (1992) and Fama (1991) argue for a slightly different notion of efficiency. They define a fairly efficient market if no economic benefits can be generated. However, forecasting returns can be achieved in a general equilibrium framework or as a result of non- trading bias.

\section{1-2 The Various Market Efficiency Tests:}

\section{A- Dickey-Fuller Unit Root Tests:}

Augmented Dickey-Fuller (ADF) test is a unit root in ARMA ( $p, q)$ model with an unknown order. The ADF test checks the null hypothesis which states that $y_{t}$ time series are non-stationary (or I (1)) against the alternative hypothesis which 
predicts that these series are stationary (I (0)) assuming that the dynamic aspect of data has an ARMA structure. The ADF test is based on the estimation of the following regression:

$$
y_{t}=\beta^{\prime} d_{t}+\theta y_{t-1}+\sum_{j=1}^{p} \psi_{j} \Delta y_{t-j}+\varepsilon_{t}
$$

Where $d_{t}$ is a vector of deterministic terms (constant and slope). The lagged difference terms $p \Delta y_{t-j}$ are used to approximate the ARMA structure of errors and the $\mathrm{p}$-value is configured such that errors are uncorrelated $\varepsilon_{t}$ in a serial manner. The error term is assumed to be homoscedastic. The specification of the deterministic terms depends on the supposed behaviour of $y_{t}$ under the alternative hypothesis of stationarity of the trend. Under the null hypothesis, $y_{t}$ is I (1) which implies $\theta=1$. The t-statistic of the ADF and the standardized bias statistics are based on the least squares estimators of the regression equation above, given by:

$$
\begin{aligned}
& A D F_{t}=t_{\theta=1}=\frac{\widehat{\theta}-1}{S E(\theta)} \\
& A D F_{n}=\frac{T(\widehat{\theta}-1)}{1-\widehat{\psi_{1}}-\cdots-\widehat{\psi_{p}}}
\end{aligned}
$$

An alternative formulation of the regression of the ADF test is as follows:

$$
\Delta y_{t}=\beta^{\prime} d_{t}+\lambda y_{t-1}+\sum_{j=1}^{p} \psi_{j} \Delta y_{t-j}+\varepsilon_{t}
$$

Where $\lambda=\theta-1$. Under the null hypothesis, $\Delta y_{t}$ is I (0) which implies that $\lambda=0$. The t-statistic of ADF is then the usual tstatistic to test $\lambda=0$ and the standardized biased statistics of ADF is $T \hat{\lambda} / 1-\widehat{\psi_{1}}-\cdots-\widehat{\psi_{p}}$.

An important practical issue of implementing the ADF test is to specify lag length $p$. If $p$ is very low, then the remaining serial correlation in the errors will bias the test. If $p$ is very large, then the test power will suffer. $\mathrm{Ng}$ and Perron (1993) have suggested the following procedure for selecting the data -dependent lag length which results in stable sizes of the test with a minimum power loss. First, we determine an upper limit $p_{\max }$ of $\mathrm{p}$. Second, we estimate the regression of the ADF test with $p=p_{\text {max }}$. If the absolute value of the t-statistic for testing the significance of the last lagged difference is greater than 1.6, then we set $\mathrm{p}=p_{\max }$ and we will run the unit root test. Otherwise, we will reduce lag length by one unit and we repeat the procedure.

\section{B- $\quad$ Phillips-Perron Unit Root Tests:}

Phillips-Perron (1988) developed a number of unit root tests that have become popular in financial time series analysis. Phillips-Perron (PP) unit root tests primarily differ from those of ADF in how to deal with errors serial correlation and heteroskedasticity. PP tests regression is given by:

$\Delta y_{t}=\beta^{\prime} d_{t}+\lambda y_{t-1}+\mu_{t}$

Where, $\mu_{t}$ is I (0) and may be heteroscedastic. PP tests correct any errors serial correlation and heteroscedasticity $\mu_{t}$ using an OLS estimation and modifying test statistics $t_{\lambda=0}$ and $T \hat{\lambda}$.. These modified statistics denoted $Z_{t}$ and $Z_{\lambda}$ are given by:

$Z_{t}=\left(\frac{\hat{S}^{2}}{\widehat{\omega}^{2}}\right)^{1 / 2} t_{\lambda=1}-\frac{1}{2}\left(\frac{\widehat{\omega}^{2}-\hat{S}^{2}}{\widehat{\omega}^{2}}\right)\left(\frac{T \cdot S E(\widehat{\lambda})}{\hat{S}^{2}}\right)$

$Z_{\lambda}=T \hat{\lambda}-\frac{1}{2} \frac{T^{2} S E(\widehat{\lambda})}{S^{2}}\left(\widehat{\omega}^{2}-\hat{S}^{2}\right)$

Since we used k lags in auto-covariances, the Newey-West estimator can be used to produce consistent estimates of variance parameters, 


$$
\begin{aligned}
& \hat{S}^{2}=T^{-1} \sum_{t=1}^{T} \hat{\mu}_{t}^{2} \\
& \widehat{\omega}^{2}=\hat{v}_{0}+2 \sum_{j=1}^{k}\left[1-\frac{j}{(k+1)}\right] \hat{v}_{j}
\end{aligned}
$$

Où,

$$
\hat{v}_{j}=T^{-1} \sum_{t=j+1}^{T} \hat{\mu}_{t} \hat{\mu}_{t-j}
$$

The estimated values of $\lambda$ and its standard errors have been obtained from OLS of equation (5). Sample variance of the least squares residual $u \hat{~ i s ~ a ~ c o n s i s t e n t ~ e s t i m a t o r ~ o f ~} \sigma^{2}$ and Newey-West estimator of long-term variance of $u$ using $u ̂$ is a consistent estimator of $\omega^{2}$.

Under the null hypothesis which states that $\lambda=0$, the $Z_{t}$ and $Z_{\lambda}$ statistics of PP test have the same asymptotic distribution as the ADF t-statistic and the standardized biased statistics. A comparative advantage of PP tests on ADF tests is that PP tests are robust to heteroskedasticity general forms in error terms $u_{t}$. Another advantage is that the researcher is not forced to specify a lag length for the test regression.

\section{C- Stationarity Tests:}

More recently, DeJong et al (1992) and Diebold and Rudebusch (1991) found poor evidence against the standard ADF unit root and PP tests when the data exhibit a stable auto-regressive tendency with roots close to unit or when data are fractionally integrated. To circumvent this poor weak evidence, we will include in addition to unit root tests the stationarity test which checks the null hypothesis against the alternative of non-stationarity.

On the one hand, a result of a unit root in data is concluded if the null hypothesis of the ADF and PP tests is not rejected while the null hypothesis of the stationarity test is rejected. On the other hand, if the stationarity test does not reject the null hypothesis and the ADF and PP tests reject the null hypothesis of a unit root, then rejecting a random walk hypothesis is strengthened.

The KPSS test stationarity test proposed by Kwiatkowski, Phillips, Schmidt and Shin (1992) is most commonly used. The test consists in $y_{t}, \mathrm{t}=1,2, \ldots, \mathrm{T}$, the observed series. It is assumed that the $y_{t}$ series can be decomposed into a sum of a deterministic trend, a random walk and a stationary error or,

$y_{t}=\beta t+r_{t}+e_{t}$

Where $r_{t}=r_{t-1}+\varepsilon_{t}$, $\varepsilon_{t} \sim W N\left(0, \sigma_{\varepsilon}^{2}\right)$

$r_{t}$ is I (0) and its initial value $r_{0}$ is considered fixed and plays the same role of the constant term of the regression equation. Note that $r_{t}$ is a pure random walk with an innovation variance $\sigma_{\varepsilon}^{2}$.

The null hypothesis is that $y_{t}$ has a stationary trend formulated as follows:

$$
H_{0}: \sigma_{\varepsilon}^{2}=0
$$

Implying that $r_{t}$ is constant.

KPSS test statistic is the Lagrange Multiplier test (LM) to check $\sigma_{\varepsilon}^{2}=0$ against the alternative $\sigma_{\varepsilon}^{2}>0$ and it is given by calculating the partial sum of the residuals $\left(e_{t}\right)$ generated in the $y_{t}$ regression, by fixing the constant and the time slope each time. Let $\hat{\sigma}_{\varepsilon}^{2}$ the error variannce estimator and $\hat{S}_{t}$ the partial sum of residuals. We calculate the LM statistic as follows: 
$L M=\frac{T^{-2} \sum_{t=1}^{T} \hat{S}^{2}}{\widehat{\sigma}^{2}(l)}$

Où $\hat{S}_{t}=\sum_{i=1}^{t} e_{i} \quad t=1,2, \ldots, T$

$\hat{\sigma}^{2}(l)$ is an asymptotically consistent estimator of $\hat{\sigma}_{\varepsilon}^{2}$ and is estimated as follows:

$\hat{\sigma}^{2}(l)=T^{-1} \sum_{t=1}^{T} e_{t}^{2}+2 T^{-1} \sum_{s=l}^{l} w(s, l) \sum_{t=s+1}^{T} e_{t} e_{t-s}$

Where $w(s, l)$ is an optional lag window. Kwiatkowski, Phillips, Schmidt and Shin (1992) used Bartlett window $(w(s, l)=$ $\left.1-\frac{S}{1+l}\right)$ and showed that the test statistic in equation (10) has an asymptotic distribution equal to a Brownian Bridge function for the degree and trend of stationarity. For degree of stationarity, the distribution of equation (10) is shown as follows:

$\hat{\eta}_{r} \stackrel{d}{\rightarrow} \int_{0}^{1} v(r)^{2} d r$

Where $v(r)=w(r)-r w(1)$.

$w(r)$ is a Wiener process (Brownian movement). It should be noted that while testing stationarity of residuals in equation (10), we calculate residuals using the following subtraction: $e_{t}=y_{t}-\bar{y}$. For stationarity of the trend, the asymptotic distribution is given by:

$\hat{\eta}_{r} \stackrel{d}{\rightarrow} \int_{0}^{1} v_{2}(r)^{2} d r$

Where second-order Brownian Bridge $v(r)$ is given by:

$v_{2}(r)=w(r)+\left(2 r-3 r^{2}\right) w(1)+\left(-6 r+6 r^{2}\right) \int_{0}^{1} w(r) d r$

The critical values of the upper tail of equations (12) and (13) are reported in the Appendices of Kwiatkowski, Phillips, Schmidt and Shin (1992).

\section{D- $\quad$ The Variance Ratio Test:}

To expose some elements of the theory of variance ratio test, let $x_{t}$ a stochastic process that satisfies the following recurrence relation:

$y_{t}=\mu+y_{t-1}+\varepsilon_{t}, \quad E\left(\varepsilon_{t}\right)=0$ pour tout $t$

Where

$\Delta y_{t}=\mu+\varepsilon_{t}, \Delta y_{t}=y_{t}-y_{t-1}$

Where, deviation $\mu$ is an arbitrary parameter. The random walk hypothesis posits the restriction that errors $\varepsilon_{t}$ are uncorrelated or that innovations are unpredictable from past innovations.

Lo and MacKinlay (1988) developed the random walk test under two null hypotheses: the Gaussian increments are i.i.d and in general increments are uncorrelated but weakly dependent and possibly heteroscedastic.

\section{D-1 The Null Hypothesis of Gaussian i.i.d:}

Let the null hypothesis which denotes the case where innovations are normally, randomly and identically distributed variables with variance $\sigma^{2}$ and we assume that we have $\mathrm{nq}+1$ observations $\left(y_{0}, y_{1}, \ldots, y_{n q}\right.$ of $\left.y_{t}\right)$ where $\mathrm{n}$ and $\mathrm{q}$ are integers greater than the unit. Consider the following estimators of the unknown parameters $\mu$ and $\sigma^{2}$ : 
$\hat{\mu} \equiv \frac{1}{n q} \sum_{k=1}^{n q}\left[y_{k}-y_{k-1}\right] \equiv \frac{1}{n q}\left[y_{k}-y_{0}\right]$

$\hat{\sigma}_{a} \equiv \frac{1}{n q} \sum_{k=q}^{n q}\left[y_{k}-y_{k-1}-\hat{\mu}\right]^{2}$

The estimator $\hat{\sigma}_{a}$ is simply the sample variance of the first difference $y_{t}$. Consider the variance of the qth differences of $y_{t}$, which is under the null hypothesis $H_{1}$ is $\mathrm{q}$ times the variance of the first differences. Dividing by $\mathrm{q}$, we obtain the estimator $\hat{\sigma}_{b}^{2}(q)$ which also converges to $\sigma^{2}$ under $H_{1}$ where:

$\hat{\sigma}_{b}^{2}(q) \equiv \frac{1}{n q^{2}}\left[y_{k}-y_{k-q}-q \mu\right]^{2}$

The estimator $\hat{\sigma}_{b}^{2}(q)$ is written as a function of $q$ to highlight the fact that the distinct alternative estimator of $\sigma^{2}$ can be formed for each q. Under the null hypothesis of the Gaussian random walk $\hat{\sigma}_{a}$ et $\hat{\sigma}_{b}^{2}(q)$ should be almost equal. However, the random walk test is performed by calculating the difference $H_{d}(q)=\hat{\sigma}_{b}^{2}(q)-\hat{\sigma}_{a}^{2}$ and checking its proximity to zero. Alternatively, a test may also be based on the $H_{r}(q)=\frac{\widehat{\sigma}_{b}^{2}}{\widehat{\sigma}_{a}^{2}}-1$ ratio which converges to zero probability. Lo and Mackinlay (1988) showed that $H_{r}(q)$ has the following limit distribution under the null hypothesis $H_{1}$ :

$\sqrt{n q} H_{r}(q) \sim N\left(0, \frac{2(2 q-1)(q-1)}{3 q}\right)$

\section{D-2 The Heteroscedastic Null Hypothesis:}

Under the conditions that enable a variety of heteroscedasticity forms by including ARCH processes, Lo and Mackinlay (1988) showed the limit distribution $H_{r}(q)$ of variance ratio as an approximate linear combination of autocorrelation where:

$H_{r}(q) \sim N(0, v(q))$

Où $\hat{v}(q)=\sum_{j=1}^{q-1}\left(\frac{2(q-j)}{q}\right)^{2} \hat{\delta}(j)$

And $\hat{\delta}(j)$ are estimators consistent with the heteroskedasticity of the asymptotic variance of autocorrelation of $\Delta x_{t}$ defined as,

$\hat{\delta}(j)=\sum_{k=j+1}^{n q} \frac{\left(x_{k}-x_{k-1}-\widehat{u}\right)^{2}\left(x_{k-j}-x_{k-j-1}-\widehat{u}\right)^{2}}{\left(\sum_{k=1}^{n q}\left(x_{k}-x_{k-1}-\widehat{u}\right)^{2}\right)^{2}}$

The test of the null hypothesis of heteroscedasticity (equation (21)) under the standardized variance ratio $z_{2}(q)$ may be defined as follows:

$z_{2}(q)=\sqrt{n q} H_{r}(q) \cdot \hat{v}^{-0.5}(\mathrm{q}) \sim \mathrm{N}(0,1)$

Also, the null hypothesis of homoscedasticity (equation (21)) under the standardized variance ratio may be specified as follows:

$z_{2}(q)=\sqrt{n q} H_{r}(q)\left(\frac{2(2 q-1)(q-1)}{3 q}\right) \sim N(0,1)$

\section{PRESENTATION OF DATA AND HYPOTHESES OF THE STUDY}

\section{2-1 Presentation of data}

We will consider 28 market indices across three main regions: the Americas, Europe and Pacific Asia. The following table shows the different indices by region:

Table 1. Market indices by region 


\begin{tabular}{|c|c|c|}
\hline Country & Market index & Study period \\
\hline \multicolumn{3}{|c|}{ (A) The Americas } \\
\hline Brazil & BVSP & From $28 / 04 / 1993$ to $22 / 03 / 2012$ \\
\hline Mexico & MXX & From $09 / 09 / 1991$ to $22 / 03 / 2012$ \\
\hline Argentina & MERV & From $18 / 10 / 1996$ to $22 / 03 / 2012$ \\
\hline United States & IXIC & From $03 / 01 / 1991$ to $22 / 03 / 2012$ \\
\hline United States & NYA & From $03 / 01 / 1991$ to $22 / 03 / 2012$ \\
\hline United States & GSPC & From $03 / 01 / 1991$ to $22 / 03 / 2012$ \\
\hline Canada & GSPTSE & From $15 / 10 / 1999$ to $22 / 03 / 2012$ \\
\hline \multicolumn{3}{|c|}{ (B) Asia and pacific } \\
\hline Australia & AORD & From 03/01/1991 to $22 / 03 / 2012$ \\
\hline India & BSESN & From $10 / 07 / 1997$ to $22 / 03 / 2012$ \\
\hline Indonesia & JKSE & From $29 / 09 / 1997$ to $22 / 03 / 2012$ \\
\hline Malaysia & KLSE & From $17 / 12 / 1993$ to $22 / 03 / 2012$ \\
\hline China & $\mathrm{HSI}$ & From 03/01/1991 to $22 / 03 / 2012$ \\
\hline South Korea & KS11 & From $22 / 07 / 1997$ to $22 / 03 / 2012$ \\
\hline Japan & N225 & From $03 / 01 / 1991$ to $22 / 03 / 2012$ \\
\hline New Zealand & NZ50 & From $16 / 04 / 2004$ to $22 / 03 / 2012$ \\
\hline Singapore & STI & From $03 / 01 / 1991$ to $22 / 03 / 2012$ \\
\hline & (C) Euro & 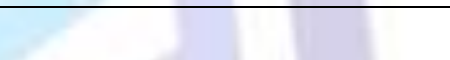 \\
\hline Netherlands & AEX & From $19 / 03 / 1992$ to $22 / 03 / 2012$ \\
\hline Greece & GDAT & From $27 / 08 / 1999$ to $22 / 03 / 2012$ \\
\hline Osterich & ATX & From $11 / 11 / 1992$ to $22 / 03 / 2012$ \\
\hline Belgium & BFX & From $13 / 07 / 2005$ to $22 / 03 / 2012$ \\
\hline France & CAC40 & From $03 / 01 / 1991$ to $22 / 03 / 2012$ \\
\hline Great Britain & FTSE & From $03 / 01 / 1991$ to $22 / 03 / 2012$ \\
\hline Germany & GDAXI & From $03 / 01 / 1991$ to $22 / 03 / 2012$ \\
\hline Ireland & ISEQ & From $22 / 02 / 2005$ to $22 / 03 / 2012$ \\
\hline Denmark & OMX20 & From $24 / 08 / 1999$ to $22 / 03 / 2012$ \\
\hline Sweden & OMXSPI & From $28 / 07 / 2000$ to $22 / 03 / 2012$ \\
\hline Norway & OSEAX & From $23 / 11 / 2000$ to $22 / 03 / 2012$ \\
\hline Switzerland & SSMI & From $03 / 01 / 1991$ to $22 / 03 / 2012$ \\
\hline
\end{tabular}


We will run different tests on indices returns. The data frequency is daily and all time series are extracted from the Yahoo website! Finance.

\section{2-2 The Hypotheses:}

Our empirical validation aims at testing the following hypotheses:

- Hypothesis 1: Market indices returns follow a random walk,

- Hypothesis 2: Markets do not follow a random walk.

In what follows, we will, first, describe of the characteristics of our data, and second, we will perform market efficiency tests to, finally, accept or reject our hypotheses.

\section{THE RESULTS AND THEIR INTERPRETATION:}

\section{3-1 Time Series Descriptive Statistics:}

\section{A. Descriptive Statistics of The Americas Time Series:}

The table below reports the descriptive statistics of market indices time series of the American region:

Table 2. Descriptive statistics of the American indices

\begin{tabular}{|c|c|c|c|c|c|c|c|}
\hline Statistics & BVSP & MXX & MERV & IXIC & NYA & GSPC & GSPTSE \\
\hline Mean & 0.0018022 & 0.0007779 & 0.0006431 & 0.0004734 & 0.0003181 & 0.0003197 & 0.0002061 \\
\hline Maximum & 0.3341902 & 0.1292305 & 0.174879 & 0.141732 & 0.1221624 & 0.1158004 & 0.982332 \\
\hline Minimum & -0.89845 & -0.1333713 & -0.1372661 & -0.0966851 & -0.0972599 & -0.0903498 & -0.0932419 \\
\hline Skewness & -6.272653 & 0.1997595 & -0.0462153 & 0.111911 & -0.1742552 & -0.0521658 & $-0,4841973$ \\
\hline Kurtosis & 230.5999 & 8.476871 & 8.475638 & 8.959549 & 13.98683 & 11.76749 & 11.21868 \\
\hline Median & 0.0017032 & 0.0008004 & 0.0010047 & 0.0011907 & 0.0005893 & 0.0005455 & 0.0004455 \\
\hline Stand.Dev & 0.0282416 & 0.0161521 & 0.0220416 & 0.0158404 & 0.0115862 & 0.0119112 & 0.0124824 \\
\hline
\end{tabular}

For the seven market indices in the American region, statistics of time series returns leads to the following results. Mean returns range between 0.0002061 (GSPTSE) and 0.0018022 (BVSP). However, maximum values range between 0.1158004 (GSPC) and 0.982332 (GSPTSE) and minimum values between -0.1372661 (MERV) and -0.0903498 (GSPC). Standard deviations are relatively low and vary between 0.0115862 (NYA) and 0.0282416 (BVSP).

Concerning the distributions, we found negative skewness values for all indices except MXX and IXIC. Consequently, returns distributions are skewed to the right of the median and the left tail is thicker unlike MXX and IXIC distributions. Kurtosis values are all greater than 3 and, therefore, all are leptokurtic distributions.

Descriptive statistics of Asia and the Pacific time series:

The table below reports the descriptive statistics of the Asian and Pacific region time series: 
Table 3. Descriptive statistics of the Asian and Pacific region time series

\begin{tabular}{|c|c|c|c|c|c|c|c|c|c|c|}
\hline statistics & AORD & BSESN & JKSE & KLSE & HSI & KS11 & N225 & NZ50 & STI & AEX \\
\hline Mean & 0.0002458 & 0.0005299 & 0.000636 & 0.0002213 & 0.0005003 & 0.0004792 & -0.000582 & 0.0001668 & 0.0002197 & 0.000179 \\
\hline Maximum & 0.0625435 & 0.1733933 & 0.1402848 & 0.231427 & 0.1882361 & 0.1194567 & 0.141503 & 0.0598694 & 0.1373919 & 0.1054834 \\
\hline Minimum & -0.0819798 & -0.1113855 & -0.1195465 & -0.2145778 & -0.1370044 & -0.120188 & -0.1140637 & -0.0481815 & -0.0880363 & -0.5288609 \\
\hline Skewness & -0.4430534 & 0.0988917 & 0.0461594 & 1.60679 & 0.2930094 & -0.0182987 & -0.0080231 & -0.3090767 & 0.1695039 & -6.998369 \\
\hline Kurtosis & 9.18916 & 8.752431 & 9.668231 & 55.35855 & 12.65016 & 6.736776 & 8.192862 & 8.011036 & 11.21816 & 235.6404 \\
\hline Median & 0.0004109 & 0.0010796 & 0.0008556 & 0.0002322 & 0.0005528 & 0.0010649 & -0.000551 & 0.0005407 & 0.0000929 & 0.0006717 \\
\hline Stand. Dev & 0.0094236 & 0.0171127 & 0.0178188 & 0.0158579 & 0.0171139 & 0.0204013 & 0.0153521 & 0.0076041 & 0.0131327 & 0.0161934 \\
\hline
\end{tabular}

The statistics of returns time series of the ten market indices in the Asia and the Pacific region leads to the following observations. Mean returns range between -0.000582 (N225) and 0.000636 (JKSE). However, maximum values range between 0.0598694 (NZ50) and 0.1882361 (HSI) and minimum values vary between -0.5288609 (AEX) and 0.0481815 (NZ50). Standard deviations have relatively high values ranging between 0.0076041 (NZ50) and 0.0204013 (KS11).

However, skewness values are positive for BSESN, JKSE, KLSE, HSI and STI, therefore indices distributions spread out to the left of the median and right tails are thicker. The remaining indices spread to the right. kurtosis values are all greater than 3 therefore the distributions are leptokurtic.

Descriptive statistics of the time series in Europe:

The table below shows the descriptive statistics of the time series of the European market: 
Table 4. Descriptive statistics of the time series of the European market

\begin{tabular}{|c|c|c|c|c|c|c|c|c|c|c|c|}
\hline statistics & GDAT & ATX & BFX & CAC40 & FTSE & GDAXI & ISEQ & OMX20 & OMXSPI & OSEAX & SSMI \\
\hline Mean & 0.1081349 & 0.0003172 & -0.0000667 & 0.0002295 & 0.0002312 & 0.0003777 & -0.0001944 & 0.0002682 & 0.0001684 & 0.000447 & 0.0003195 \\
\hline Maximum & 337.7611 & 0.1277341 & 0.1125995 & 0.1117617 & 0.0983867 & 0.1140195 & 0.1143015 & 0.0996188 & 0.0901212 & 0.0962159 & 0.1139101 \\
\hline Minimum & -0.0970972 & -0.0974456 & -0.0798263 & -0.0903682 & -0.0884835 & -0.0939938 & -0.1389079 & -0.1106211 & -0.076805 & -0.0925243 & 0.0804078 \\
\hline Skewness & 55.73082 & -0.1987437 & 0.307573 & 0.1040866 & 0.0298575 & 0.0350987 & -0.2596184 & -0.0579527 & 0.1210649 & -0.4478925 & 0.0061739 \\
\hline Kurtosis & 3106.95 & 10.95916 & 10.9323 & 7.859053 & 9.144151 & 7.859948 & 9.283923 & 8.242414 & 6.783472 & 8.311725 & 9.176103 \\
\hline Median & 0 & 0.0006793 & 0.0001894 & 0.0003375 & 0.0003788 & 0.0007575 & 0.0002696 & 0.0000622 & 0.0003522 & 0.0010971 & 0.0007145 \\
\hline Stand. Dev & 6.057615 & 0.0138934 & 0.0145679 & 0.014413 & 0.0116611 & 0.014756 & 0.0182772 & 0.0135883 & 0.014879 & 0.0155458 & 0.011907 \\
\hline
\end{tabular}

The study of the statistics of the returns time series of the eleven European market indices leads to the following results. Mean returns range between -0.0001944 (ISEQ) and 0.1081349 (GDAT). Maximum values and minimum values vary respectively between 0.0901212 (OMXSPI) and 337.7611 (GDAT) for the maximum values and -0.1389079 (ISEQ) and -0.076805 (OMXSPI). We notice that the minimum values are all negative. Standard deviations have relatively high values ranging between 0.0116611 (FTSE) and 6.057615 (GDAT).

Concerning returns distributions, we found negative skeweness values for ATX, ISEQ, OMX20 and OSEAX and positive values for the remaining indices. Kurtosis values are greater

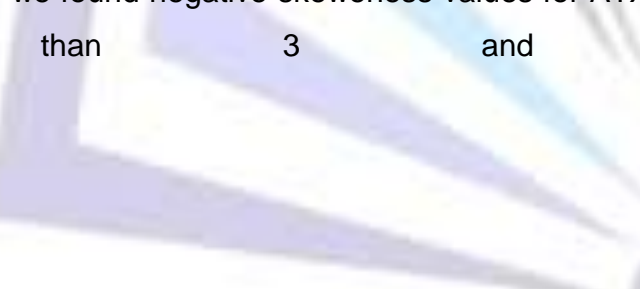

therefore

the

distributions

are

leptokurtic. 


\section{3-2 The Results and Their Interpretations}

A. The unit root test

A-1 The American region :

The table below reports the two unit root tests, the ADF and PP, for the American market indices.

Table 5. Unit root tests for the American region

\begin{tabular}{|c|c|c|c|c|c|c|c|c|}
\hline \multirow{2}{*}{$\begin{array}{r}A . \\
\text { Index }\end{array}$} & \multicolumn{4}{|c|}{ Dickey-Fuller1 Test } & \multicolumn{4}{|c|}{ Phillips-Perron Test } \\
\hline & $\begin{array}{c}\text { Test } \\
\text { statistics }\end{array}$ & $\begin{array}{c}\text { Critical } \\
\text { value } \\
(1 \%)\end{array}$ & $\begin{array}{c}\text { Critical } \\
\text { value } \\
(5 \%)\end{array}$ & $\begin{array}{c}\text { Critical } \\
\text { value } \\
(10 \%)\end{array}$ & $\begin{array}{c}\text { Test } \\
\text { statistics }\end{array}$ & $\begin{array}{c}\text { Critical } \\
\text { value } \\
(1 \%)\end{array}$ & $\begin{array}{c}\text { Critical } \\
\text { value } \\
(5 \%)\end{array}$ & $\begin{array}{c}\text { Critical } \\
\text { value } \\
(10 \%)\end{array}$ \\
\hline BVSP & -48.722 & -3.430 & -2.860 & -2.570 & -70.541 & -3.430 & -2.860 & -2.570 \\
\hline MXX & -49.036 & -3.430 & -2.860 & -2.570 & -69.577 & -3.430 & -2.860 & -2.570 \\
\hline MERV & -40.590 & -3.430 & -2.860 & -2.570 & -58.347 & -3.430 & -2.860 & -2.570 \\
\hline IXIC & -50.723 & -3.430 & -2.860 & -2.570 & -73.083 & -3.430 & -2.860 & -2.570 \\
\hline NYA & -50.362 & -3.430 & -2.860 & -2.570 & -71.832 & -3.430 & -2.860 & -2.570 \\
\hline GSPC & -50.393 & -3.430 & -2.860 & -2.570 & -72.396 & -3.430 & -2.860 & -2.570 \\
\hline GSPTSE & -36.549 & -3.430 & -2.860 & -2.570 & -55.901 & -3.430 & -2.860 & -2.570 \\
\hline
\end{tabular}

The ADF and PP statistics reported in Table (5) have absolute values greater than the critical values (at the $1 \%, 5 \%$ and $10 \%$ levels). This implies that the two tests reject the null hypothesis of unit root and then market indices time series do not follow a random walk.

\section{A-2 The Asia and Pacific Region:}

The table below reports the results of the two tests:

1 ADF test is based on one lag. 
ISSN:2321-1098

Table 6.Unit root tests of the Asia and the Pacific market indices

\begin{tabular}{|c|c|c|c|c|c|c|c|c|}
\hline \multirow{2}{*}{$\begin{array}{r}A . \\
\text { Index }\end{array}$} & \multicolumn{4}{|c|}{ Dickey-Fuller Test } & \multicolumn{4}{|c|}{ Phillips-Perron Test } \\
\hline & $\begin{array}{c}\text { Test } \\
\text { statistics }\end{array}$ & $\begin{array}{c}\text { Critical } \\
\text { value } \\
(1 \%)\end{array}$ & $\begin{array}{c}\text { Critical } \\
\text { value } \\
(5 \%)\end{array}$ & $\begin{array}{c}\text { Critical } \\
\text { value } \\
(10 \%)\end{array}$ & $\begin{array}{c}\text { Test } \\
\text { statistics }\end{array}$ & $\begin{array}{c}\text { Critical } \\
\text { value } \\
(1 \%)\end{array}$ & $\begin{array}{c}\text { Critical } \\
\text { value } \\
(5 \%)\end{array}$ & $\begin{array}{c}\text { Critical } \\
\text { value } \\
(10 \%)\end{array}$ \\
\hline AORD & -51.889 & -3.430 & -2.860 & -2.570 & -71.849 & -3.430 & -2.860 & -2.570 \\
\hline BSESN & -39.042 & -3.430 & -2.860 & -2.570 & -57.912 & -3.430 & -2.860 & -2.570 \\
\hline JKSE & -42.785 & -3.430 & -2.860 & -2.570 & -61.611 & -3.430 & -2.860 & -2.570 \\
\hline KLSE & -44.533 & -3.430 & -2.860 & -2.570 & -69.034 & -3.430 & -2.860 & -2.570 \\
\hline $\mathrm{HSI}$ & -52.312 & -3.430 & -2.860 & -2.570 & -74.223 & -3.430 & -2.860 & -2.570 \\
\hline KS11 & -43.953 & -3.430 & -2.860 & -2.570 & -62.922 & -3.430 & -2.860 & -2.570 \\
\hline N225 & -49.892 & -3.430 & -2.860 & -2.570 & -72.021 & -3.430 & -2.860 & -2.570 \\
\hline NZ50 & -23.399 & -3.430 & -2.860 & -2.570 & -39.256 & -3.430 & -2.860 & -2.570 \\
\hline STI & -51.443 & -3.430 & -2.860 & -2.570 & -73.672 & -3.430 & -2.860 & -2.570 \\
\hline
\end{tabular}

Like the American markets, Asian and Pacific indices time series do not follow a random walk as the absolute values of the two tests are greater than the critical values.

\section{A-3 Europe:}

The table below reports the statistics of the two unit root tests for the European indices: 
Table 7. Unit root tests for the European indices

\begin{tabular}{|c|c|c|c|c|c|c|c|c|}
\hline \multirow{2}{*}{$\begin{array}{r}A . \\
\text { Index }\end{array}$} & \multicolumn{4}{|c|}{ Dickey-Fuller Test } & \multicolumn{4}{|c|}{ Phillips-Perron Test } \\
\hline & $\begin{array}{c}\text { Test } \\
\text { statistics }\end{array}$ & $\begin{array}{c}\text { Critical } \\
\text { value } \\
(1 \%)\end{array}$ & $\begin{array}{c}\text { Critical } \\
\text { value } \\
(5 \%)\end{array}$ & $\begin{array}{c}\text { Critical } \\
\text { value } \\
(10 \%)\end{array}$ & $\begin{array}{c}\text { Test } \\
\text { statistics }\end{array}$ & $\begin{array}{c}\text { Critical } \\
\text { value } \\
(1 \%)\end{array}$ & $\begin{array}{c}\text { Critical } \\
\text { value } \\
(5 \%)\end{array}$ & $\begin{array}{c}\text { Critical } \\
\text { value } \\
(10 \%)\end{array}$ \\
\hline AEX & -46.512 & -3.430 & -2.860 & -2.570 & -67.079 & -3.430 & -2.860 & -2.570 \\
\hline GD.AT & -13850.265 & -3.430 & -2.860 & -2.570 & -52.486 & -3.430 & -2.860 & -2.570 \\
\hline ATX & -42.149 & -3.430 & -2.860 & -2.570 & -61.665 & -3.430 & -2.860 & -2.570 \\
\hline BFX & -17.533 & -3.430 & -2.860 & -2.570 & -29.579 & -3.430 & -2.860 & -2.570 \\
\hline CAC40 & -50.981 & -3.430 & -2.860 & -2.570 & -71.458 & -3.430 & -2.860 & -2.570 \\
\hline FTSE & -51.611 & -3.430 & -2.860 & -2.570 & -73.828 & -3.430 & -2.860 & -2.570 \\
\hline GDAXI & -50.942 & -3.430 & -2.860 & -2.570 & -72.502 & -3.430 & -2.860 & -2.570 \\
\hline ISEQ & -22.069 & -3.430 & -2.860 & -2.570 & -34.578 & -3.430 & -2.860 & -2.570 \\
\hline OMX20 & -33.486 & -3.430 & -2.860 & -2.570 & -54.128 & -3.430 & -2.860 & -2.570 \\
\hline OMXSPI & -32.579 & -3.430 & -2.860 & -2.570 & -50.608 & -3.430 & -2.860 & -2.570 \\
\hline OSEAX & -30.268 & -3.430 & -2.860 & -2.570 & -48.158 & -3.430 & -2.860 & -2.570 \\
\hline SSMI & -51.509 & -3.430 & -2.860 & -2.570 & -72.211 & -3.430 & -2.860 & -2.570 \\
\hline
\end{tabular}

European indices time series are not different from the other markets. We found absolute values greater than critical values at the $1 \%, 5 \%$ and $10 \%$ levels and therefore these time series do not follow a random walk.

B. Stationarity Test (KPSS) :

\section{B-1 American Region:}

The table below reports the results of the KPSS test for the American region: 
Table 8. KPSS test results for the American region

\begin{tabular}{|l|l|l|l|l|l|}
\hline \multirow{3}{*}{ Index } & \multicolumn{5}{|c|}{ KPSS Test } \\
\cline { 2 - 6 } & \multicolumn{1}{|c|}{$\begin{array}{c}\text { Test } \\
\text { statistics } \\
\left(1^{\text {st }} \text { order }\right)\end{array}$} & $\begin{array}{r}\text { Critical } \\
\text { value } \\
(1 \%)\end{array}$ & $\begin{array}{c}\text { Critical } \\
\text { value } \\
(2.5 \%)\end{array}$ & $\begin{array}{r}\text { Critical } \\
\text { value } \\
(5 \%)\end{array}$ & $\begin{array}{r}\text { Critical } \\
\text { value } \\
(10 \%)\end{array}$ \\
\hline BVSP & 0.153 & 0.216 & 0.176 & 0.146 & 0.119 \\
\hline MXX & 0.101 & 0.216 & 0.176 & 0.146 & 0.119 \\
\hline MERV & 0.701 & 0.216 & 0.176 & 0.146 & 0.119 \\
\hline IXIC & 0.0347 & 0.216 & 0.176 & 0.146 & 0.119 \\
\hline NYA & 0.0489 & 0.216 & 0.176 & 0.146 & 0.119 \\
\hline GSPC & 0.0478 & 0.216 & 0.176 & 0.146 & 0.119 \\
\hline GSPTSE & 0.0281 & 0.216 & 0.176 & 0.146 & 0.119 \\
\hline
\end{tabular}

KPSS test statistics allow us to reject the null hypothesis of stationarity for MXX, IXIC, NYA, GSPC and GSPTSE. However, this hypothesis is accepted for MERV at the $1 \%$ level and for BVSP at the $5 \%$ level. Therefore, we conclude that, except for MERV and BVSP, American indices time series are not stationary.

\section{B-2- Asia and Pacific region:}

Table 9 reports KPSS test results for the Asian and Pacific time series.

Table 9. KPSS test results for the Asian and Pacific time series

\begin{tabular}{|c|c|c|c|c|c|}
\hline A. & & & $\overline{\text { KPSS Tes }}$ & & \\
\hline Index & $\begin{array}{c}\text { Test } \\
\text { statistics } \\
\left(1^{\text {st }} \text { order }\right)\end{array}$ & $\begin{array}{c}\text { Critical } \\
\text { value } \\
(1 \%)\end{array}$ & $\begin{array}{l}\text { Critical } \\
\text { value } \\
(2.5 \%)\end{array}$ & $\begin{array}{c}\text { Critical } \\
\text { value } \\
(5 \%)\end{array}$ & $\begin{array}{c}\text { Critical } \\
\text { value } \\
(10 \%)\end{array}$ \\
\hline AORD & 0.0917 & 0.216 & 0.176 & 0.146 & 0.119 \\
\hline BSESN & 0.328 & 0.216 & 0.176 & 0.146 & 0.119 \\
\hline JKSE & 0.133 & 0.216 & 0.176 & 0.146 & 0.119 \\
\hline KLSE & 0.0565 & 0.216 & 0.176 & 0.146 & 0.119 \\
\hline $\mathrm{HSI}$ & 0.0418 & 0.216 & 0.176 & 0.146 & 0.119 \\
\hline KS11 & 0.0978 & 0.216 & 0.176 & 0.146 & 0.119 \\
\hline N225 & 0.121 & 0.216 & 0.176 & 0.146 & 0.119 \\
\hline NZ50 & 0.0774 & 0.216 & 0.176 & 0.146 & 0.119 \\
\hline STI & 0.139 & 0.216 & 0.176 & 0.146 & 0.119 \\
\hline
\end{tabular}


The null hypothesis of stationarity is accepted for AORD, KLSE, HSI, KS11, NZ50, and therefore these series are stationary. However, the null hypothesis of stationarity is rejected for STI, BSESN, JKSE (at 10 $\%)$ and N225 (at $2.5 \%)$.

\section{B-3-Europe :}

KPSS test results for the European time series are reported in the following table:

Table 10. KPSS test results for the European time series

\begin{tabular}{|l|l|l|l|l|l|}
\hline \multirow{2}{*}{ Index } & \multicolumn{5}{|c|}{ KPSS Test } \\
\cline { 2 - 6 } & $\begin{array}{c}\text { Test } \\
\text { statistics } \\
\left(1^{\text {st }} \text { order }\right)\end{array}$ & $\begin{array}{c}\text { Critical } \\
\text { value } \\
(1 \%)\end{array}$ & $\begin{array}{c}\text { Critical } \\
\text { value } \\
(2.5 \%)\end{array}$ & $\begin{array}{r}\text { Critical } \\
\text { value } \\
(5 \%)\end{array}$ & $\begin{array}{r}\text { Critical } \\
\text { value } \\
(10 \%)\end{array}$ \\
\hline AEX & 0.165 & 0.216 & 0.176 & 0.146 & 0.119 \\
\hline GD.AT & 0.0816 & 0.216 & 0.176 & 0.146 & 0.119 \\
\hline ATX & 0.104 & 0.216 & 0.176 & 0.146 & 0.119 \\
\hline BFX & 0.0341 & 0.216 & 0.176 & 0.146 & 0.119 \\
\hline CAC40 & 0.0945 & 0.216 & 0.176 & 0.146 & 0.119 \\
\hline FTSE & 0.0712 & 0.216 & 0.176 & 0.146 & 0.119 \\
\hline GDAXI & 0.0689 & 0.216 & 0.176 & 0.146 & 0.119 \\
\hline ISEQ & 0.083 & 0.216 & 0.176 & 0.146 & 0.119 \\
\hline OMX20 & 0.0238 & 0.216 & 0.176 & 0.146 & 0.119 \\
\hline OMXSPI & 0.0217 & 0.216 & 0.176 & 0.146 & 0.119 \\
\hline OSEAX & 0.0737 & 0.216 & 0.176 & 0.146 & 0.119 \\
\hline & 0.0849 & 0.216 & 0.176 & 0.146 & 0.119 \\
\hline & & & & & \\
\hline
\end{tabular}

European indices time series are stationary except for AEX (at 5\%). Test statistics are inferior to the critical values, hence the null hypothesis of stationarity is accepted.

\section{Heteroscedasticity Test :}

\section{C-1 American Region :}

The table below reports the results of the Breusch-Pagan/Cooke-Weisberg test for the American time series. 
Tableau 11. Breusch-Pagan/Cooke-Weisberg test results for the American time series.

\begin{tabular}{|l|l|l|}
\hline \multirow{2}{*}{} & \multicolumn{2}{|c|}{ Breusch-Pagan/Cook-Weisberg Test } \\
\cline { 2 - 3 } & \multicolumn{1}{|c|}{ Test statistics } & \multicolumn{1}{c|}{ Probability } \\
\hline BVSP & 2.56 & 0.1100 \\
\hline MXX & 0.19 & 0.6640 \\
\hline MERV & 0.44 & 0.5083 \\
\hline IXIC & 1.04 & 0.3082 \\
\hline NYA & 0.26 & 0.6130 \\
\hline GSPC & 1.27 & 0.2605 \\
\hline GSPTSE & 0.07 & 0.7963 \\
\hline
\end{tabular}

This table indicates that American indices time series have multiplying errors variance. Test probability is greater than $10 \%$ and therefore we reject the null hypothesis of homoscedasticity.

\section{C-2 Asia and The Pacific:}

The table below reports the results of Breusch-Pagan/Cooke-Weisberg test for the Asian and Pacific time series.

Table 12. Breusch-Pagan/Cooke-Weisberg test results for the Asian and Pacific time series.

\begin{tabular}{|l|c|c|}
\hline \multirow{2}{*}{} & \multicolumn{2}{|c|}{ Breusch-Pagan/Cook-Weisberg Test } \\
\cline { 2 - 3 } & Test statistics & Probability \\
\hline AORD & 0.00 & 0.9582 \\
\hline BSESN & 0.01 & 0.9216 \\
\hline JKSE & 0.07 & 0.7905 \\
\hline KLSE & 0.16 & 0.6861 \\
\hline HSI & 0.09 & 0.7666 \\
\hline KS11 & 4.52 & 0.0336 \\
\hline N225 & 0.02 & 0.8867 \\
\hline NZ50 & 0.00 & 0.9587 \\
\hline STI & 0.42 & 0.5189 \\
\hline
\end{tabular}

Test results for the Asian and Pacific markets are similar to those of the American markets except for KS11. We reject the null hypothesis of homoscedasticity of errors because test probabilities are greater than 10\%. Then, except for KS11, Asian and Pacific time series score heteroscedasticity of errors.

\section{C-3 Europe :}


The table below reports the results of the Breusch-Pagan/Cooke-Weisberg test for the European time series.

Table 13.The Breusch-Pagan/Cooke-Weisberg test results for the European time series.

\begin{tabular}{|c|c|c|}
\hline A. Index & Breusc & ok-Weisberg Test \\
\hline & Test statistics & Probability \\
\hline AEX & 1.39 & 0.2383 \\
\hline GD.AT & 0.00 & 0.9887 \\
\hline ATX & 0.07 & 0.7985 \\
\hline BFX & 0.03 & 0.8697 \\
\hline CAC40 & 1.23 & 0.2681 \\
\hline FTSE & 0.01 & 0.9249 \\
\hline GDAXI & 1.07 & 0.3018 \\
\hline ISEQ & 0.19 & 0.6660 \\
\hline OMX20 & 0.47 & 0.4945 \\
\hline OMXSPI & 0.11 & 0.7357 \\
\hline OSEAX & 0.02 & 0.8770 \\
\hline SSMI & 0.07 & 0.7881 \\
\hline
\end{tabular}

This table reports test probabilities greater than $10 \%$. Therefore, we reject the null hypothesis of homoscedasticity and we confirm that all European indices time series have homoscedastic errors.

D. Variance Ratio Test:

\section{D-1 The American Region :}

The variance ratio test is the most important phase of this empirical validation. It allows for directly testing the null hypothesis of a random walk. Table 14 reports the results of the variance ratio test of Lo and Mackinlay (1988) for the American indices with four different lags (2, 4, 8 and 16). 
Table 14. The results of the variance ratio test for the American indices

\begin{tabular}{|c|c|c|c|c|c|}
\hline Index & $\begin{array}{c}\text { Variance ratios } \\
\text { and test } \\
\text { statistics }\end{array}$ & $q=2$ & $q=4$ & $q=8$ & $q=16$ \\
\hline \multirow{3}{*}{ BVSP } & $1+\widehat{M}_{r}(q)$ & 0.513072 & 0.257657 & 0.124149 & 0.064237 \\
\hline & $Z^{*}(q)$ & -1.474392 & -1.498148 & -1.514164 & -1.508026 \\
\hline & Probability & 0.1404 & 0.1341 & 0.1300 & 0.1315 \\
\hline \multirow{3}{*}{ MXX } & $1+\widehat{M}_{r}(q)$ & 0.578428 & 0.276981 & 0.141123 & 0.70210 \\
\hline & $Z^{*}(q)$ & -14.39407 & -14.59292 & -12.23212 & -9.616706 \\
\hline & Probability & 0.0000 & 0.0000 & 0.0000 & 0.0000 \\
\hline \multirow{3}{*}{ MERV } & $1+\widehat{M}_{r}(q)$ & 0.527815 & 0.261471 & 0.130949 & 0.066960 \\
\hline & $Z^{*}(q)$ & -14.23237 & -13.00500 & -10.64920 & -8.223592 \\
\hline & Probability & 0.0000 & 0.0000 & 0.0000 & 0.0000 \\
\hline \multirow{3}{*}{ IXIC } & $1+\widehat{M}_{r}(q)$ & 0.517405 & 0.246712 & 0.125737 & 0.059729 \\
\hline & $Z^{*}(q)$ & -16.25325 & -14.54991 & -11.50355 & -8.692580 \\
\hline & Probability & 0.0000 & 0.0000 & 0.0000 & 0.0000 \\
\hline \multirow{3}{*}{ NYA } & $1+\widehat{M}_{r}(q)$ & 0.500772 & 0.241185 & 0.118165 & 0.057187 \\
\hline & $Z^{*}(q)$ & -13.72165 & -11.76113 & -9.099101 & -6.684634 \\
\hline & Probability & 0.0000 & 0.0000 & 0.0000 & 0.0000 \\
\hline \multirow{3}{*}{ GSPC } & $1+\widehat{M}_{r}(q)$ & 0.489955 & 0.235684 & 0.115832 & 0.056431 \\
\hline & $Z^{*}(q)$ & -14.95326 & -12.78079 & -9.989827 & -7.392619 \\
\hline & Probability & 0.0000 & 0.0000 & 0.0000 & 0.0000 \\
\hline \multirow{3}{*}{ GSPTSE } & $1+\widehat{M}_{r}(q)$ & 0.510744 & 0.242816 & 0.119165 & 0.060301 \\
\hline & $Z^{*}(q)$ & -10.84967 & -9.910644 & -7.755761 & -5.597701 \\
\hline & Probability & 0.0000 & 0.0000 & 0.0000 & 0.0000 \\
\hline
\end{tabular}

The probabilities of the different lags of Lo and Mackinlay (1992) conducted on the different American indices time series (except BVSP) indicate that these time series do not follow a random walk. Except for BVSP, all probabilities are null and inferior to $1 \%$, hence we reject the null hypothesis of a random walk.

\section{D-2 Asia and Pacific Region:}

Table 15 reports the results of the variance ratio test of Lo and Mackinlay (1988) for Asia and the Pacific with four different lags (2, 4, 8 and 16). 
Table 15. The results of the variance ratio test for Asia and the Pacific

\begin{tabular}{|c|c|c|c|c|c|}
\hline $\begin{array}{l}\text { A. } \\
\text { Index }\end{array}$ & $\begin{array}{c}\text { Variance ratios } \\
\text { and test } \\
\text { statistics }\end{array}$ & $q=2$ & $q=4$ & $q=8$ & $q=16$ \\
\hline \multirow{3}{*}{ AORD } & $1+\widehat{M}_{r}(q)$ & 0.501422 & 0.249272 & 0.125361 & 0.063467 \\
\hline & $Z^{*}(q)$ & -17.61083 & -15.18500 & -11.71526 & -8.849948 \\
\hline & Probability & 0.0000 & 0.0000 & 0.0000 & 0.0000 \\
\hline \multirow{3}{*}{ BSESN } & $1+\widehat{M}_{r}(q)$ & 0.557953 & 0.264466 & 0.128428 & 0.067343 \\
\hline & $Z^{*}(q)$ & -14.87488 & -14.14609 & -11.41550 & -8.762600 \\
\hline & Probability & 0.0000 & 0.0000 & 0.0000 & 0.0000 \\
\hline \multirow{3}{*}{ JKSE } & $1+\widehat{M}_{r}(q)$ & 0.570094 & 0.298686 & 0.147637 & 0.071309 \\
\hline & $Z^{*}(q)$ & -13.70231 & -12.93724 & -10.80344 & -8.515112 \\
\hline & Probability & 0.0000 & 0.0000 & 0.0000 & 0.0000 \\
\hline \multirow{3}{*}{ KLSE } & $1+\widehat{M}_{r}(q)$ & 0.484474 & 0.263696 & 0.124670 & 0.064015 \\
\hline & $Z^{*}(q)$ & -5.131935 & -4.659883 & -4.269951 & -3.776571 \\
\hline & Probability & 0.0000 & 0.0000 & 0.0000 & 0.0002 \\
\hline \multirow{3}{*}{$\mathrm{HSI}$} & $1+\widehat{M}_{r}(q)$ & 0.509964 & 0.261202 & 0.124401 & 0.063540 \\
\hline & $Z^{*}(q)$ & -12.94403 & -11.15562 & -9.145024 & -7.739354 \\
\hline & Probability & 0.0000 & 0.0000 & 0.0000 & 0.0000 \\
\hline \multirow{3}{*}{ KS11 } & $1+\widehat{M}_{r}(q)$ & 0.553726 & 0.276595 & 0.130947 & 0.065444 \\
\hline & $Z^{*}(q)$ & -15.97898 & -14.66985 & -11.75248 & -8.869579 \\
\hline & Probability & 0.0000 & 0.0000 & 0.0000 & 0.0000 \\
\hline \multirow{3}{*}{ N225 } & $1+\widehat{M}_{r}(q)$ & 0.504235 & 0.245351 & 0.121283 & 0.062728 \\
\hline & $Z^{*}(q)$ & -17.76304 & -14.93889 & -11.65063 & -8.998419 \\
\hline & Probability & 0.0000 & 0.0000 & 0.0000 & 0.0000 \\
\hline \multirow{3}{*}{ NZ50 } & $1+\widehat{M}_{r}(q)$ & 0.560354 & 0.268464 & 0.127625 & 0.067666 \\
\hline & $Z^{*}(q)$ & -9.496947 & -8.601077 & -6.916072 & -5.242910 \\
\hline & Probability & 0.0000 & 0.0000 & 0.0000 & 0.0000 \\
\hline \multirow{3}{*}{ STI } & $1+\widehat{M}_{r}(q)$ & 0.526697 & 0.271819 & 0.137618 & 0.068935 \\
\hline & $Z^{*}(q)$ & -15.14406 & -13.44317 & -11.16493 & -8.913606 \\
\hline & Probability & 0.0000 & 0.0000 & 0.0000 & 0.0000 \\
\hline
\end{tabular}


The probabilities of the variance ratio test of the different lags are null or almost null (inferior to $1 \%$ ) for the Asian and Pacific time series and then we reject the null hypothesis of a random walk. Therefore, the Asian and pacific indices time series do not follow a random walk.

\section{D-3 Europe:}

Table 16 reports the results of the variance ratio test of Lo and Mackinlay (1988) for the European indices with four different lags $(2,4,8$ and 16$)$.

Table 16.The results of the variance ratio test for the European indices

\begin{tabular}{|c|c|c|c|c|c|}
\hline Index & $\begin{array}{c}\text { Variance ratios } \\
\text { and test } \\
\text { statistics }\end{array}$ & $q=2$ & $q=4$ & $q=8$ & $q=16$ \\
\hline \multirow{3}{*}{ AEX } & $1+\widehat{M}_{r}(q)$ & 0.508782 & 0.242556 & 0.121397 & 0.062911 \\
\hline & $Z^{*}(q)$ & -2.718267 & -2.778850 & -2.735924 & -2.675438 \\
\hline & Probability & 0.0066 & 0.0055 & 0.0062 & 0.0075 \\
\hline \multirow{3}{*}{ GD.AT } & $1+\widehat{M}_{r}(q)$ & 0.503114 & 0.251103 & 0.126433 & 0.063415 \\
\hline & $Z^{*}(q)$ & -1.019394 & -1.024271 & -1.024064 & -1.024598 \\
\hline & Probability & 0.3080 & 0.3057 & 0.3058 & 0.3056 \\
\hline \multirow{3}{*}{ ATX } & $1+\widehat{M}_{r}(q)$ & 0.551123 & 0.269832 & 0.133812 & 0.067303 \\
\hline & $Z^{*}(q)$ & -14.43883 & -13.00665 & -10.24269 & -7.595761 \\
\hline & Probability & 0.0000 & 0.0000 & 0.0000 & 0.0000 \\
\hline \multirow{3}{*}{ BFX } & $1+\widehat{M}_{r}(q)$ & 0.744171 & 0.248143 & 0.124155 & 0.061491 \\
\hline & $Z^{*}(q)$ & -8.303242 & -8.160258 & -6.501331 & -4.881997 \\
\hline & Probability & 0.0000 & 0.0000 & 0.0000 & 0.0000 \\
\hline \multirow{3}{*}{ CAC40 } & $1+\widehat{M}_{r}(q)$ & 0.515210 & 0.239834 & 0.121692 & 0.060957 \\
\hline & $Z^{*}(q)$ & -18.45817 & -16.40312 & -12.52707 & -9.367254 \\
\hline & Probability & 0.0000 & 0.0000 & 0.0000 & 0.0000 \\
\hline \multirow{3}{*}{ FTSE } & $1+\widehat{M}_{r}(q)$ & 0.515244 & 0.232177 & 0.117691 & 0.061425 \\
\hline & $Z^{*}(q)$ & -17.49077 & -15.26873 & -11.35386 & -8.374632 \\
\hline & Probability & 0.0000 & 0.0000 & 0.0000 & 0.0000 \\
\hline \multirow{4}{*}{ GDAXI } & $1+\widehat{M}_{r}(q)$ & 0.508529 & 0.238976 & 0.122246 & 0.062353 \\
\hline & $Z^{*}(q)$ & -18.89708 & -16.54933 & -12.80609 & -9.513925 \\
\hline & Probability & 0.0000 & 0.0000 & 0.0000 & 0.0000 \\
\hline & $1+\widehat{M}_{r}(q)$ & 0.543237 & 0.263129 & 0.130944 & 0.062353 \\
\hline
\end{tabular}


ISSN:2321-1098

\begin{tabular}{|c|c|l|l|l|l|}
\hline \multirow{4}{*}{ ISEQ } & $Z^{*}(q)$ & -9.051992 & -8.756140 & -6.916769 & -5.077481 \\
\cline { 2 - 6 } & Probability & 0.0000 & 0.0000 & 0.0000 & 0.0000 \\
\hline \multirow{4}{*}{ OMX20 } & $1+\widehat{M}_{r}(q)$ & 0.540075 & 0.252058 & 0.127308 & 0.064219 \\
\cline { 2 - 6 } & $Z^{*}(q)$ & -12.92239 & -11.73288 & -9.022937 & -6.846275 \\
\cline { 2 - 6 } & Probability & 0.0000 & 0.0000 & 0.0000 & 0.0000 \\
\hline \multirow{5}{*}{ OMXSPI } & $1+\widehat{M}_{r}(q)$ & 0.525225 & 0.249984 & 0.122544 & 0.061119 \\
\cline { 2 - 6 } & $Z^{*}(q)$ & -14.23347 & -12.73117 & -10.05668 & -7.636129 \\
\cline { 2 - 6 } & Probability & 0.0000 & 0.0000 & 0.0000 & 0.0000 \\
\hline \multirow{5}{*}{ OSEAX } & $1+\widehat{M}_{r}(q)$ & 0.511143 & 0.254168 & 0.125721 & 0.061384 \\
\cline { 2 - 6 } & $Z^{*}(q)$ & -12.67455 & -10.79075 & -8.179163 & -6.065965 \\
\cline { 2 - 6 } & Probability & 0.0000 & 0.0000 & 0.0000 & 0.0000 \\
\hline \multirow{3}{*}{ SSMI } & $1+\widehat{M}_{r}(q)$ & 0.537999 & 0.250007 & 0.127266 & 0.066425 \\
\cline { 2 - 6 } & $Z^{*}(q)$ & -17.48491 & -15.49987 & -11.81157 & -8.862045 \\
\cline { 2 - 6 } & Probability & 0.0000 & 0.0000 & 0.0000 & 0.0000 \\
\hline
\end{tabular}

The null hypothesis of a random walk is rejected for all time series of the different European indices and for all lags because the probabilities are all inferior to $1 \%$. Therefore, the European indices do not follow a random walk.

Given the weakness in the unit root tests robustness, we run, in addition to ADF and PP unit root tests which test the hypothesis of random walk, the KPSS stationarity test which also tests the hypothesis of random walk. We found that the null hypothesis of unit root is rejected for all the considered 28 indices, while the KPSS test was not conclusive because it gave different results for the indices.

The null hypothesis of stationarity has been accepted for 18 indices and rejected for 10 . However, checking stationarity of time series confirms the presence of predictable components and rejects the hypothesis of random walk. Among other things, the 10 indices for which we could not accept the hypothesis of stationarity do not necessarily follow a random walk. the variance ratio test of Lo and Mackinlay (1988) was successful and conclusive: All time series of the studied 28 indices do not follow a random walk.

Moreover, we performed Breusch-Pagan/Cooke-Weisberg heteroscedasticity test to examine errors evolution. We concluded that the null hypothesis of errors homoscedasticity is rejected for 27 indices and accepted for one. This finding confirms that errors are independent variables, and consequently, there are predictable components in errors. Hence, we confirm that the 27 indices do not follow a random walk consistent with Blaga (2012) and Aga and Kocaman (2011).

Our empirical study rejects the hypothesis of random walk for all the studied indices. This rejection implies that successive price changes can be predicted from historical values. The main causes behind rejecting a random walk can be mainly lack of transparent and asymmetrical information.

Against these results, we reject our first hypothesis and accept the second. We confirm that the studied indices time series do not follow a random walk, and therefore we reject the hypothesis of financial markets efficiency in its weak form. This result corroborates those of Fama and French (1992.993), DeBondt and Thaler (2005), Lo and MacKinlay (1991), Jagadeesh and Titman (1993) and Shleifer and Vishny (1997).

371 | P a g e 


\section{ACKNOWLEDGMENTS}

Our thanks to all the people who have contributed towards development of this work.

\section{REFERENCES}

[1] Blaga, L, 2012. "Testing the financial market informational efficiency in emerging states",Review of Applied Socioeconomic Research Vol.4, Issue 2, p 181.

[2] Aga, M. et Kocaman, B., 2011. "Efficient Market Hypothesis and Emerging Capital Markets: Empirical evidence from Istanbul Stock Exchange", Journal of Financial Markets Research Issue 3.

[3] Taylor S.J..Modelling Financial Time Series.Wiley,Chichester,1986

[4] Fama, E., (1991), "Efficient Capital Markets: II", Journal of Finance, Vol.46, pp.1575-1618.

[5] Dejong D.N.J.C Nankervis, NE Savin et $\mathrm{CH}$ whiteman "Thepower problems of unit root tests in time series with autoregressive errors. J.Econometrics 53, 323-43.

[6] Diebold, F. X., \& Rudebusch, G. D. (1991). On the power of Dickey-Fuller tests against fractional alternatives. Economics Letters, 35, 155-160.

[7] Kwiatowski,Phillips,Schmidt, and Shin. (1992), Testing the null hypothesis of stationarity against the alternative of a unit root: how sure are we that economic time series root. Journal of Econometrics, 54:59-178, 1992.

[8] Lo, A. et Mackinlay A.C., (1988), "Stock market prices do not follow random walks: Evidence from a simple specification test", Review of Financial Studies, pp. 41-66.

[9] Fama, E. F. et French, K. R., « The Cross-section of Expected Stock Returns », Journal of Finance, 47, 427-465, 1992a.

[10] Fama, E. F. et French, K. R., "Common Risk Factors in the Returns on stocks and Bonds », Journal of Financial Economics, 33, 3-56, 1993.

[11] Debondt, W. F. M. et Thaler, R., « Does the Stock Market Overreact », The Journal of Finance, 40, 793-805, 2005.

[12] Shleifer, A., Vishney, R., 1997. The limits of arbitrage. Journal of Fiance 52, 35-55.

\section{Author' biography with Photo}

Name \& surname:

Islem BOUTABBA

Address $\quad: 3$ rue des Ecoles La Goulette, Tunisia

Telephone : :+21698203744

E-mail : :islemboutabba@hotmail.com

Date of birth :5 March 1980

Nationality :Tunisian

Sex : Male

Marital status : Single

\section{Education/Qualifications}

2007-2008 University of Carthage, IHEC, Masters in Finance, currency and banks.

2004-2005 University of Sousse, ISG, Mastery in finance.

\section{Employment to Date/Work Experience}

2008-present University teacher in ESC, University of Manouba.

2007-2008 Backoffice treasurer in ABC bank.

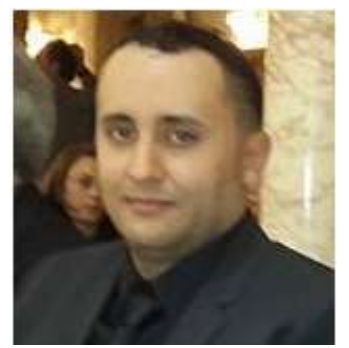

